\title{
FEASIBILITY STUDY OF MILLETS AS AN ADJUNCT IN THE BREWING INDUSTRY
}

\author{
BY \\ P N K ARIYARATNE
}

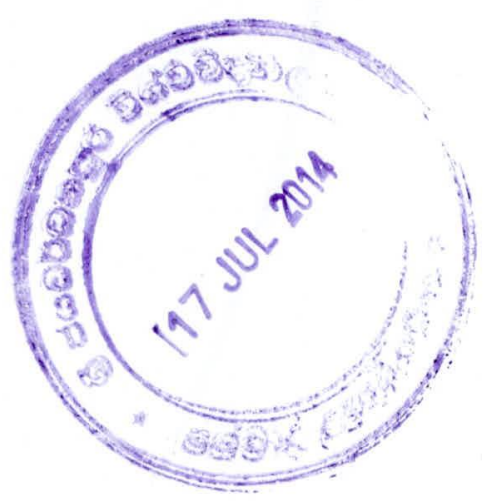

M.Sc. 


\title{
FEASIBILITY STUDY OF MILLETS AS AN ADJUNCT IN THE BREWING INDUSTRY
}

\author{
BY \\ PATHIRANNEHELAGE NALIN KUMARA \\ ARIYARATNE
}

This Thesis submitted in partial fulfillment of the requirements for the Degree in Masters of Food Science and Technology,

Department of Food Science and Technology, Faculty of Applied Science,

University of Sri Jayewardenepura, Sri Lanka 


\section{DECLARATION}

The work described in this thesis was carried out by me at Lion Brewery Ceylon PLC, Biyagama, under the supervision of Mr. Udaya Padmakumara, (QA Manager, Varun Lanka Beverage (Pvt) Ltd.) and Professor K.K.D.S.Ranaweera, (Director, Bandaranayake Memorial Ayurvedic Research Institute, and Professor of the Department of Food Science and Technology, Department of Applied Science, University of Sri Jayewardenepura, Sri Lanka,). I confirm that report on this has not been submitted in whole or in part to any University or any other institution for another Degree or Diploma.

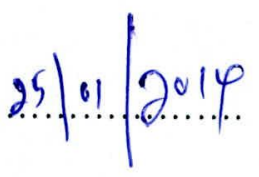

DATE

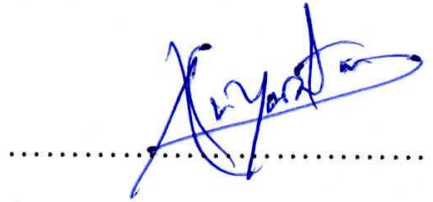

P.N.K.ARIYARATNE 
We Prof K. K. D. S. Ranaweera and Mr. Udaya Padmakumara jointly here by certify that the statement in the preceding page made by the candidate is true and that this thesis is suitable for submission to the university for the purpose of evaluation.
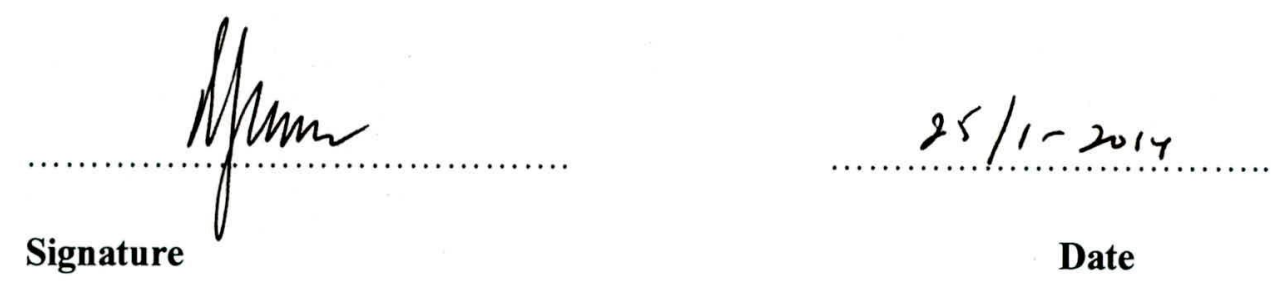

\section{Professor K.K.D.S.Ranaweera}

Director,

Bandaranayake Memorial Ayurvedic Research Institute,

Nawinna,

Maharagama.
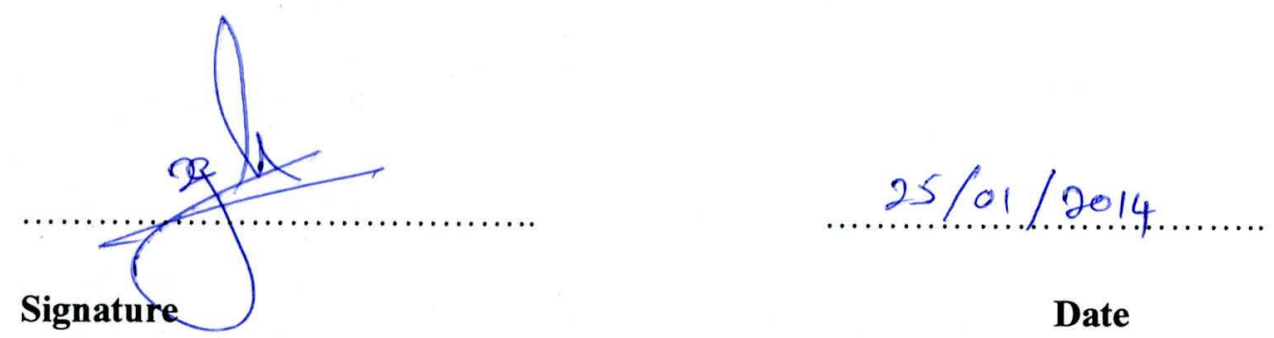

Mr. M. Udaya Padmakumara

Quality Assurance Manager,

Varun Lanka Beverage (pvt.) Ltd,

Ranala. 


\section{TABLE OF CONTENT}

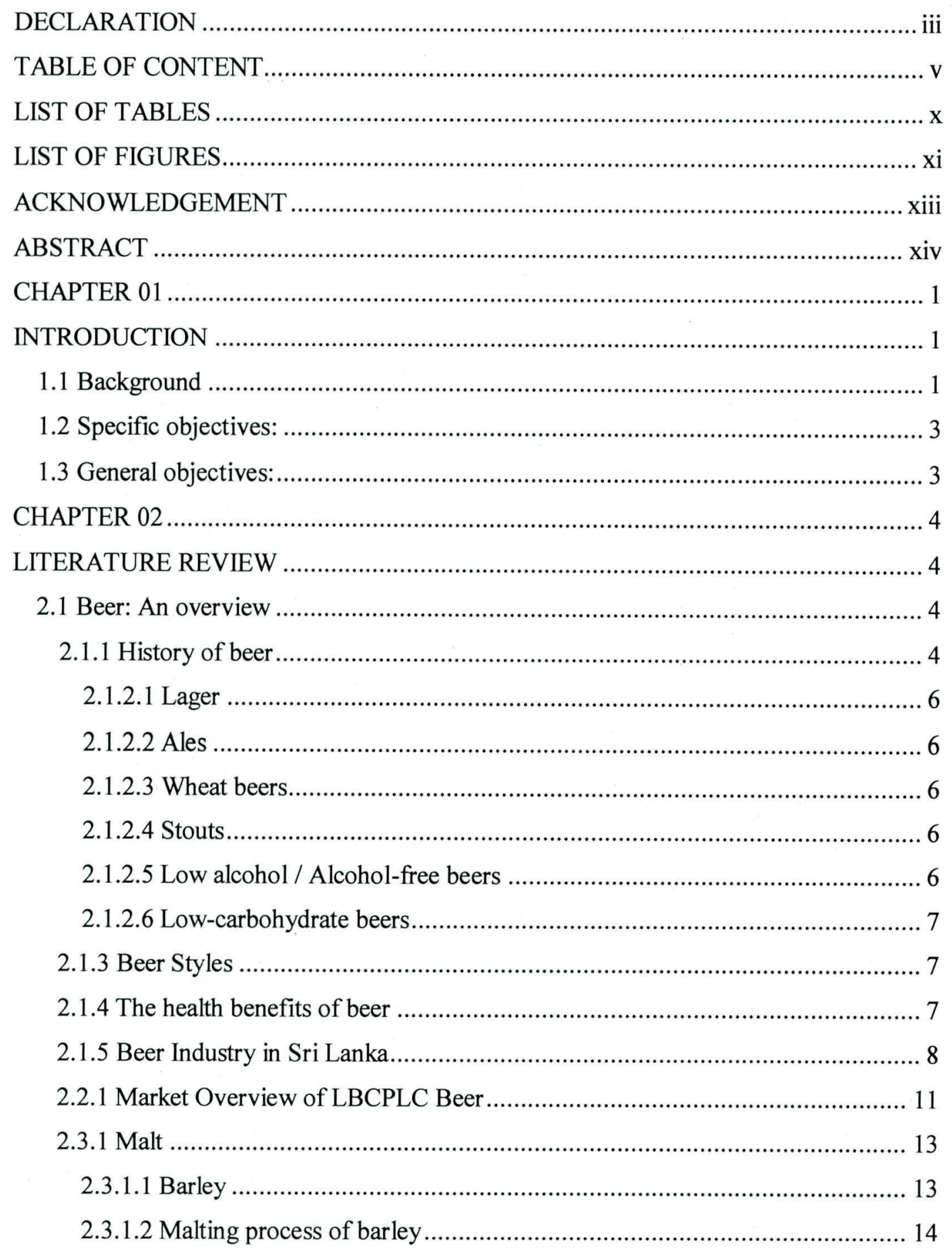




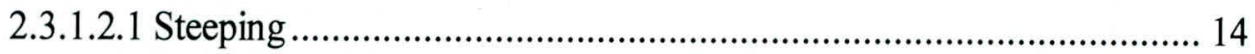

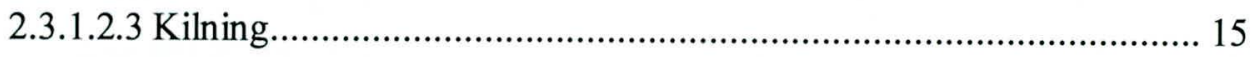

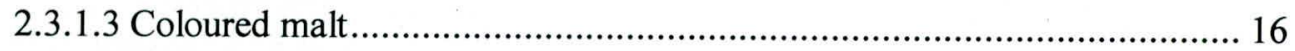

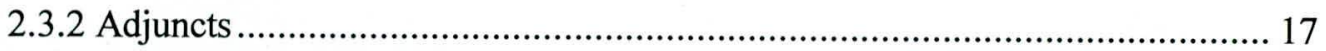

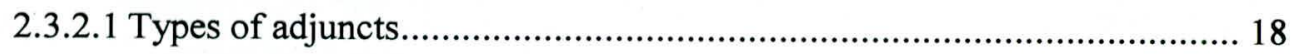

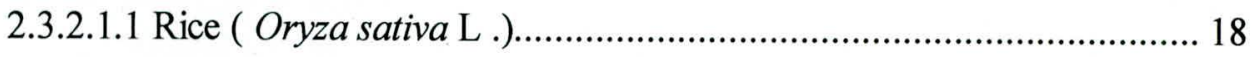

2.3.2.1.2 Maize (Zea mays L .)............................................................... 19

2.3.2.1.3 Sorghum ( Sorghum bicolor L .) .................................................... 19

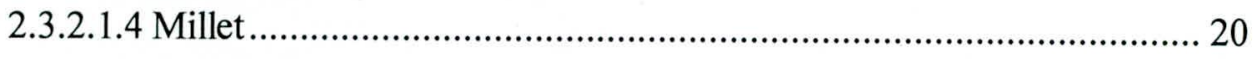

2.3.2.1.4.1 Pearl Millet ( Pennisetum glaucum ( L .) R . B r .)...................... 21

2.3.2.1.4.2 Foxtail Millet ( Setaria italica ( L .) P. Beauv.) .......................... 21

2.3.2.1.4.3 Finger Millet ( Eleusine coracana ( L .) Gaertn.)....................... 22

2.3.2.1.5 Barley ..................................................................................... 22

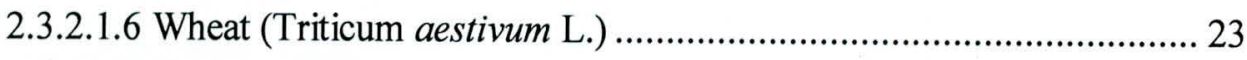

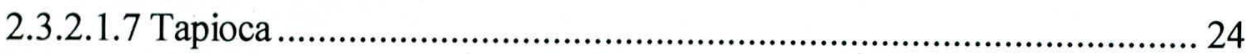

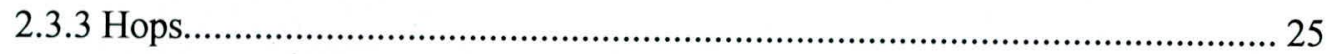

2.3.3.1 Composition and properties of the components .................................... 25

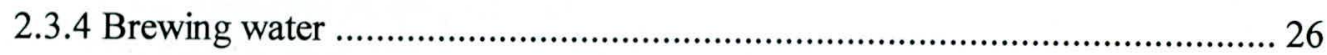

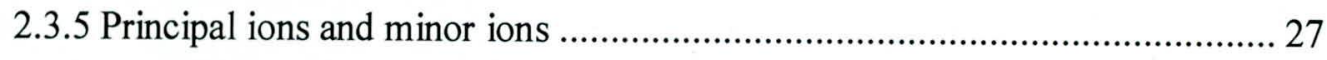

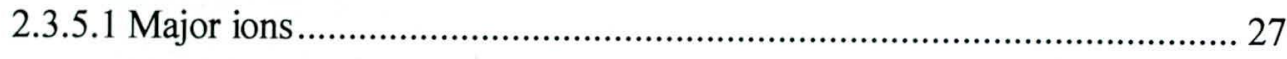

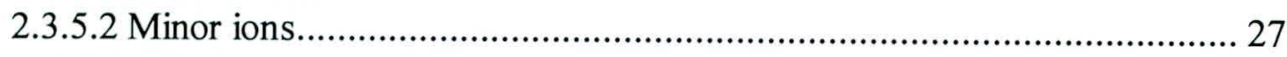

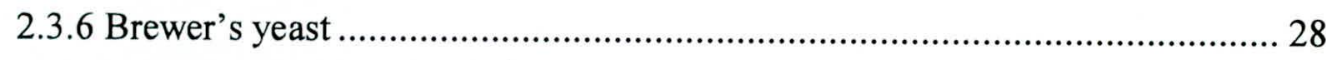

2.3.6.1 Top fermentation yeast ..................................................................... 29

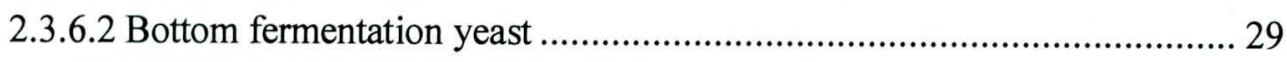

2.3.6.3 Difference of Baker's Yeast and Brewer's Yeast.................................. 29

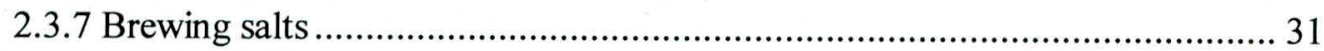

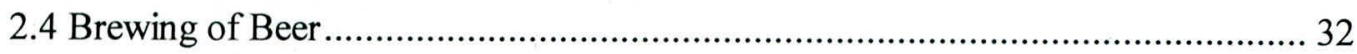

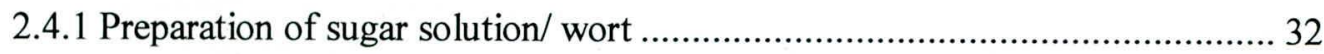

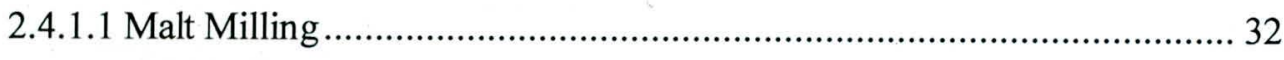

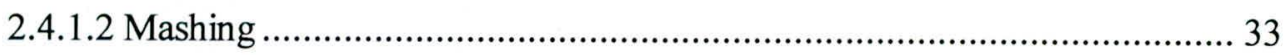




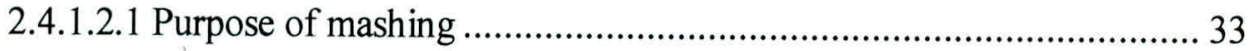

2.4.1.2.2 Properties of enzymes in Mashing ................................................... 33

2.4.1.2.2.1 Starch Degradation ..................................................................... 34

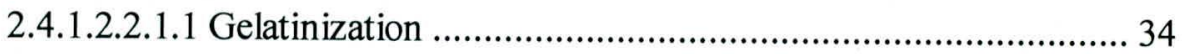

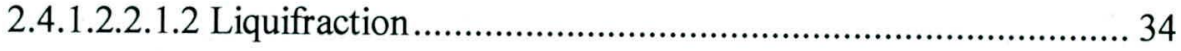

2.4.1.2.2.1.3 Saccharification .............................................................. 35

2.4.1.3 Wort Separation (Lautering) ................................................................ 35

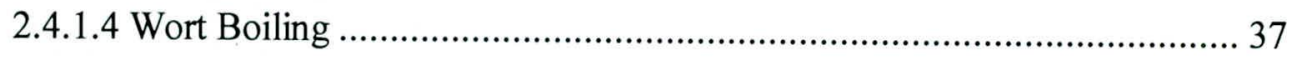

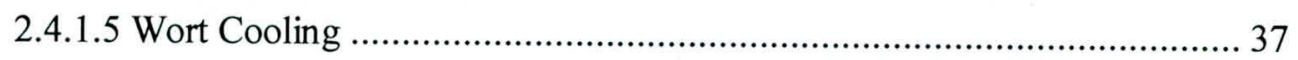

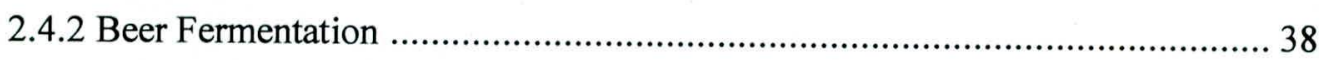

2.4.2.1 Yeast preparation \& handling........................................................... 38

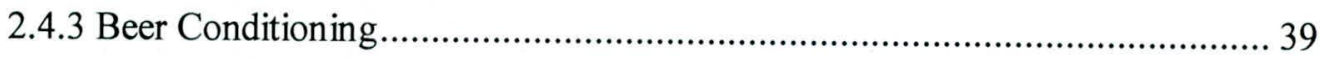

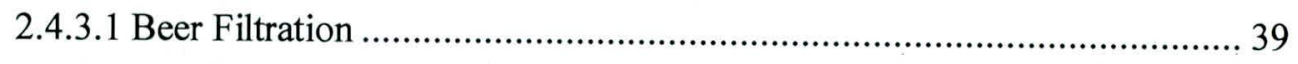

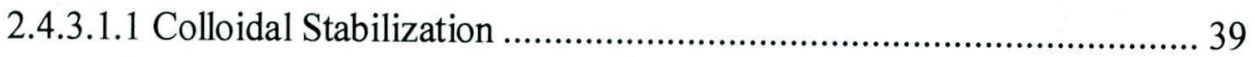

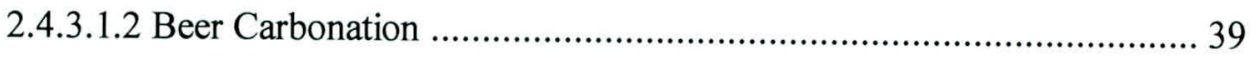

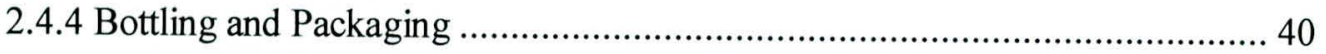

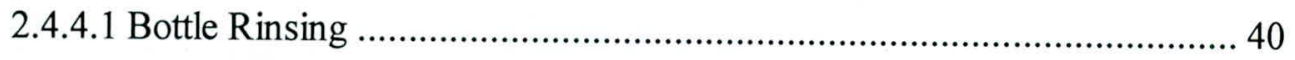

2.4.4.2 Beer packaging ................................................................................... 40

2.5 Quality Assurance System of Lion Brewery Ceylon PLC ................................. 40

2.5.1 Quality Assurance Laboratory and Chemical analysis ................................. 41

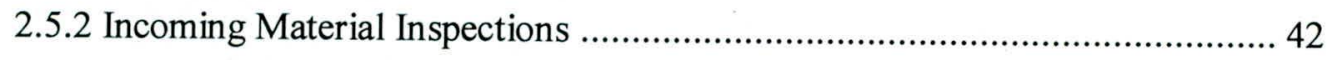

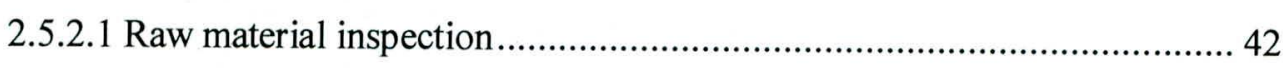

2.5.2.2 Packaging material inspection ........................................................... 43

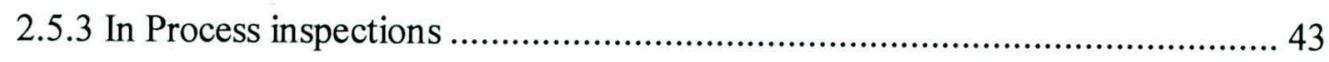

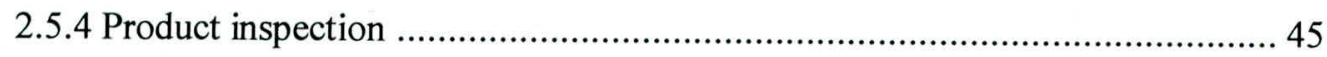

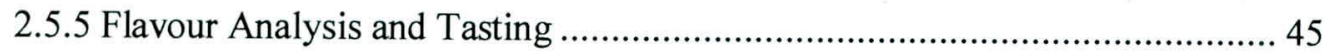

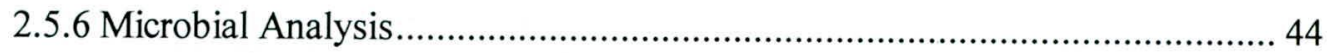

2.6 High Technology Use for Analysis in Lion Brewery Ceylon PLC ....................... 45

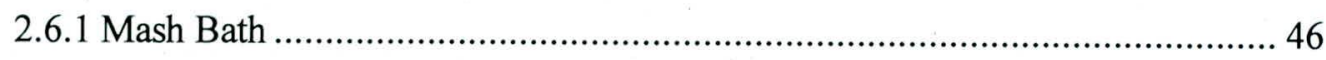

2.6.2 Laboratory Disk Mill ............................................................................. 46 


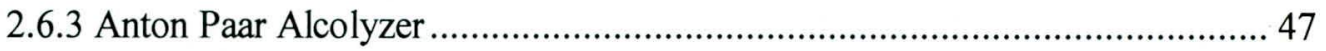

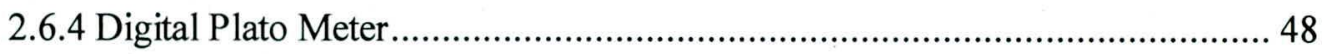

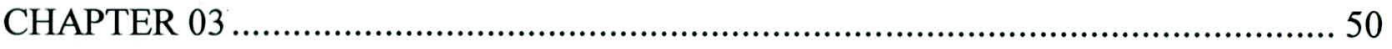

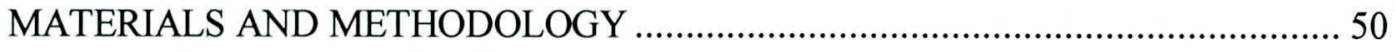

3.1 Determination of Fermentability of Millets .................................................... 50

3.3 Incorporation of best millet from sensory output as an adjunct ........................... 52

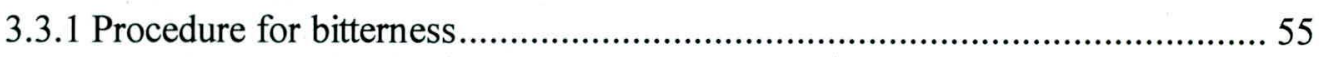

3.3.2 Procedure for Alcohol / Real degrees of fermentation / Real extract ............ 55

3.3.3 Procedure for colour ............................................................................... 55

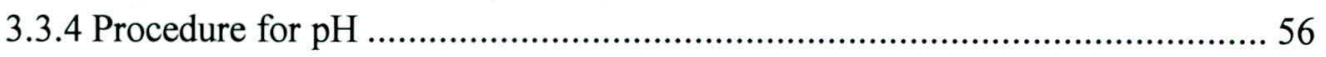

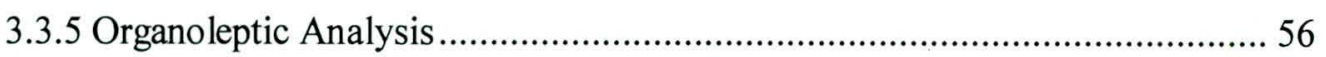

3.3.5.1 Find out the significant difference between each beer samples................ 56

3.3.5.2 Determination of sensory properties ....................................................... 56

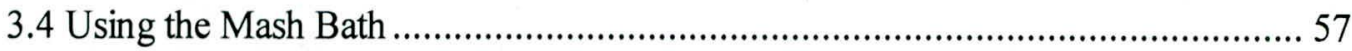

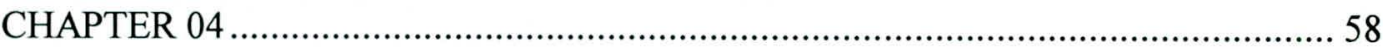

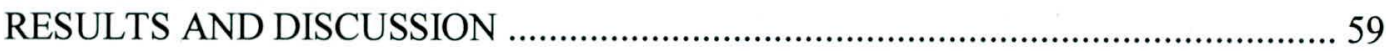

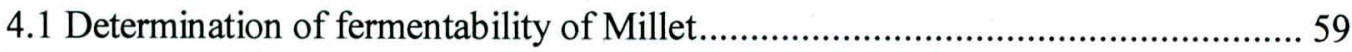

4.2 Sensory evaluations for the fermented millet samples ........................................... 60

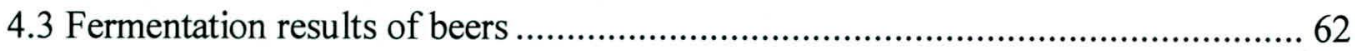

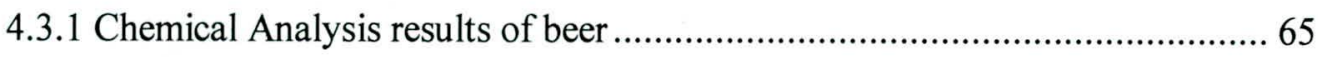

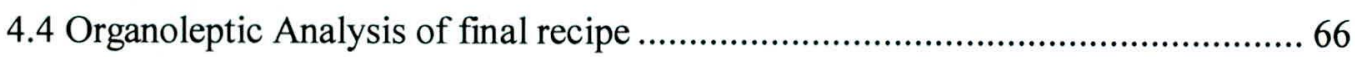

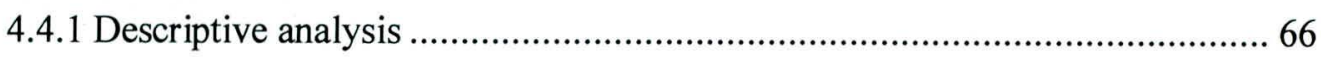

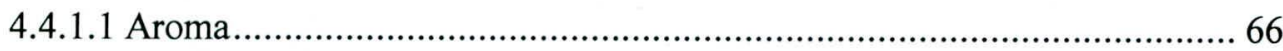

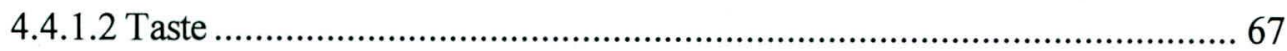

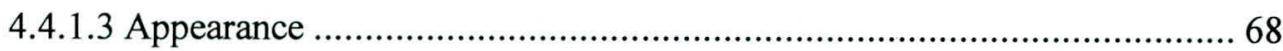

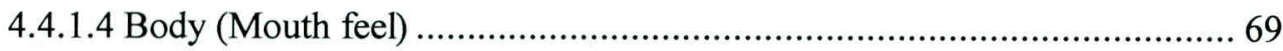

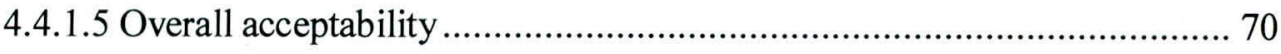

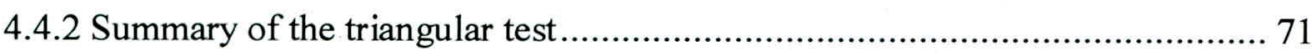

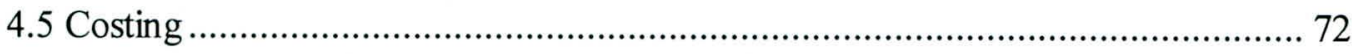

4.5.1 Cost calculations for the recipes with rice and millet .................................. 72 


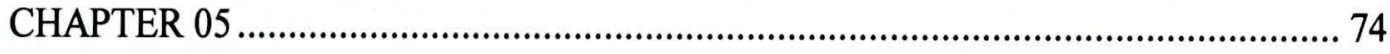

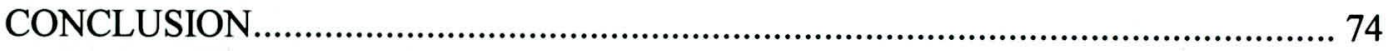

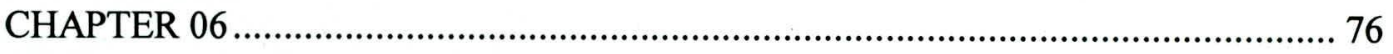

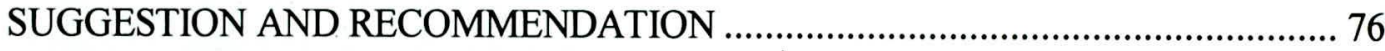

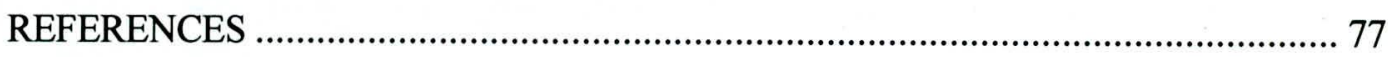

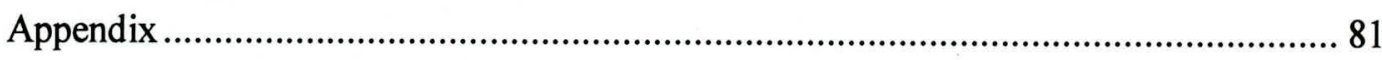




\section{LIST OF TABLES}

Tables

Pages

Table 2.1 Beer Manufacture in Litres (Millions) 08

Table 2.2 the composition of hops $\quad 26$

Table 2.3 Specification of Digital Plato meter 49

Table 3.1 Recipe Combination and condition applied 53

Table 4.1 RDF Analysis results of Three Millet Types $\quad 59$

Table 4.2 Calculated $H$ value for stimuli of three millet types 62

Table 4.3 Fermentation results of different millet adjunct \% recipes with standard recipe $\quad 64$

Table 4.4 Chemical Analysis results $\quad 65$

$\begin{array}{lll}\text { Table } & 4.5 \text { Triangular test results } & 71\end{array}$

$\begin{array}{ll}\text { Table } 4.6 \text { Grits Requirement } & 72\end{array}$

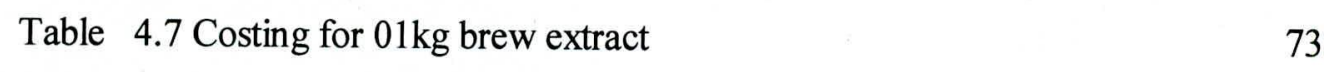




\section{LIST OF FIGURES}

Figures

Pages

Figure 2.1 Basic flow chart of beer production with the ingredients

Figure 2.2 Starch granules of Barley grain prior to germination

Figure 2.3 Steeping process of barley in steeping tanks

Figure 2.4 Germination process of barley in malting box

Figure 2.5 kilning process of malt in kilning chamber

Figure2.6 Structure of hop plant cone and indication of alpha acid in cone

Figure 2.7 Structure of yeast cell under microscope

Figure 2.8 Spider diagram of a particular brand of beer

Figure 2.9 Mash Bath

Figure 2.10 Laboratory Disk Mill

Figure 2.11 Alcolyzer

Figure 2.12 Digital Plato Meter

Figure 3.1 Mash bath

Figure 4.1 Graphical representation of the overall sensory evaluation carried out select for three millet type

Figure 4.2 Graphical representation of the overall sensory evaluation carried out select for three millet type

Figure 4.3 Fermentation trend of Millet Beer with standard 
Figure 4.4 Graphical representation of the sensory evaluation carried out pertaining to the pearl millet recipes and standard recipe.

Figure 4.5 Aroma sensory characteristic variations of beer samples $\quad 67$

Figure 4.6 Taste sensory characteristic variations of beer samples 68

Figure 4.7 appearance sensory characteristic variations of beer samples $\quad 69$

Figure 4.8 Body (mouth feel) sensory characteristic variation of beer samples $\quad 70$

Figure 4.9 Overall acceptability sensory characteristic variations of beer samples 70

Figure 4.10 sensory attribute variations of Beer samples $\quad 71$ 


\section{ACKNOWLEDGEMENT}

I am deeply indebted to my external supervisor Mr. Udaya Padmakumara-Manager Quality Assurance,Varun Beverage Lanka (pvt) Ltd.

It is my obligation to be thankful to the staff of The Lion Brewery Ceylon PLC; by whom I was given the fullest co-operation to complete my project

Dr. Eshantha Salgado- Quality assurance, Mr. Chandana De Silva- Assistant Quality assurance Manager, Mr.Mahesh Jayathunga - Assistant Brewing Manager, and my internal supervisor Prof. K.K.D.S Ranaweera for his valuable guidance and encouragement for the project and my special gratitude extended to Ms.Rupika Perera and Ms Hayesha Edirisinghe for helping me on carried out statistical analysis.

Also I would like to express my thanks to all the staff of quality assurance laboratory in The Lion Brewery Ceylon PLC. Further I offer my thanks especially for the sensory panel, for their kind support given me to complete my project work successfully.

Further I would like to thank all the members of the academic \& Non Academic staff of the Faculty of Food Science \& Technology of Sri Jayewardenepura University of Sri Lanka for their comments and suggestions to improve the quality of this research work.

Finally my thanks are due to all the people who help me in different ways to end up my project work successfully. 


\title{
FEASIBILITY STUDY OF MILLETS AS AN ADJUNCT IN THE BREWING INDUSTRY
}

\author{
BY
}

\author{
NALIN KUMARA ARIYARATNE
}

\begin{abstract}
Adjuncts are an additional source of carbohydrate extract used to partially replace or supplement the malt in beer. They are also used to reduce the overall material costs and to utilize indigenous sources. Millet is also used to produce ethanol in some countries in the world. Starch being the main ingredient in millet can be converted in to sugars which are then subjected to fermentation by yeast to make ethanol. The ratio of malt to adjunct must fall within an acceptable range. Each brewer according to the quality specifications for the final beer and the cost estimation sets adjunct ratios. Thus the major objective of this project was to study the possibility of use of millets as an adjunct for producing beer at its optimum ratio where the qualities of the product as well as the requirements in cost aspects are met.

Three millets milled separately and cooked then mashed with $\alpha$-amylase and $\beta$-amylase respectively in the three separate containers of mash bath. Filtered mash was adjusted to $12 \%$ Plato level and fermented by pitching yeast. Real degrees of the fermentation were determined through Anton paar alcolyzer. $100 \%$ fermented millet samples were analysed organoleptically with 12 well-trained panellists to select the best millet type for beer recipe optimization.
\end{abstract}

Then the optimum ratio of malt to selected millet (pearl millet) was to find. In order to replace the rice component with pearl millet $\&$ to determine the most suitable pearl millet inclusion as the adjunct, a series of malt and pearl millet combinations were selected ranging from $25 \%$ to $40 \%$. Based on the results of the experiment during brewing, fermentation and end product testing the optimum combination could be selected. For 
that, three different strong beer samples were prepared by changing the pearl millet, malt and water amount of the original recipe. The amount of Extract was calculated according to the IBD (Institute of Brewing \& Distillation) method. The pearl millet usage starting from $30 \%$ and gradually increased by $35 \%$ and finally up to $40 \%$. Then beer samples were organoleptically analysed by the well trained sensory panel. The Triangular test and deceptive test were done to identify the differences and organoleptic assessment.

Pearl millet was recorded real degree of fermentation as $79.9 \%$ and good result on overall acceptability in the sensory evaluation of fermented millet samples while finger millet gets $78.2 \%$. Out of the three recipe developed with pearl millet all gave significantly similar chemical analysis results, but sensory evaluation shows significantly different result among those three. The sample with $70 \%$ malt and $30 \%$ millet gave the best sensory results and $65 \%$ malt and $35 \%$ millet recipe was also recorded very good overall results while. $60 \%$ malt and $40 \%$ millet deviated significantly from the standard characteristics. Triangular test which was conducted for three samples Have shown positive results for both $70 \%$ malt and 30\%millet and $65 \%$ malt and $35 \%$ millet recipes, by considering cost factor $65 \%$ malt and $35 \%$ millet recipe was selected for further scale up trails. 